\section{Journal of Computer Networks, Architecture and High Performance Computing}

Volume 3, Number 2, July 2021

https://doi.org/10.47709/cnahpc.v3i2.1064
Submitted : 24 August 2021

Accepted : 25 August 2021

Published : 28 August 2021

\title{
Copyright Protection of Scientific Works using Digital Watermarking by Embedding DOI QR Code
}

\author{
Muhammad Khoiruddin Harahap ${ }^{1)}$, Nurul Khairina ${ }^{2)^{*}}$ \\ ${ }^{1)}$ Politeknik Ganesha Medan, Indonesia, ${ }^{2}$ Universitas Medan Area, Indonesia \\ ${ }^{1)}$ choir.harahap@yahoo.com, ${ }^{2}$ nurulkhairina27@gmail.com
}

\begin{abstract}
Digital identifier is a technology used to prove ownership of a work. At this time, the Digital Object Identifier is a form of implementation of the digital identifier used in every scientific work. Not infrequently there are several cases of theft of ownership or copyright of a work, both scientific works, and certain other works. Watermarking is a technique created to protect the ownership of works. Watermarking techniques can be applied to several media such as audio, video, and also documents, one of which is the Portable Document Format document file. In this study, researchers want to build copyright protection for scientific works. Researchers offer research concepts using a Digital Object Identifier which is always installed on scientific papers to be published. The Digital Object Identifier will later become the basic data in building the Quick Response Code. The Digital Object Identifier of each scientific work will not be the same as each other, this will certainly make the Quick Response Code more unique. The results show that the watermarking process in building copyright protection of scientific works can be very successful Quick Response Code can be read and detected properly without experiencing lag time. Quick Response Code readings from several variations of motion are also not very influential, so it can be concluded that distance does not limit the detection of Quick Response Codes. From this research, researchers can deduce that the watermark is performed on the scientific work not only serves as the copyright protection of that scientific paper but can also be an alternative for other researchers to access the scientific work.
\end{abstract}

Keywords: Digital Identifier; DOI; QRCode; Watermarking; Scientific Journal

\section{INTRODUCTION}

Research is an important activity for both academics and non-academics. Researchers who come from academics such as lecturers and students, are obliged to carry out research both to complete studies and fulfill lecturers' research performance. This also applies to non-academic researchers, researchers from research and development institutions owned by the government and privately owned institutions also conduct research to publish their research results. Scientific work is one of the interesting research results, each researcher competes with each other to increase the publication of scientific works both nationally and internationally.

The DOI (Digital Object Identifier) system was first introduced at the Frankfurt Book Fair in 1997. In the same year, the International DOI® Foundation (IDF) was established to develop and manage the DOI system. In 2000, through the Crossref Registration Agency, DOI had citation linking of electronic articles (Paskin, 2010). Every manager of scientific publications, both national and international, applies DOI as a digital identifier for scientific work. DOI allocated to scientific works is permanent, DOI has hyperlinks that provide information about the scientific work. DOI consists of several unique numbers that help researchers to be able to share their research or knowledge with the whole world (Khedmatgozar, 2020). Watermarking is a technology that plays a role in the copyright protection of certain works. The computerized digital watermarking technique was first introduced in 1988. In 1988, watermarking was able to maintain the confidentiality, integrity, and availability of documents, and since 1955, various innovations regarding digital watermarking have become more developed (Begum \& Uddin, 2020). Watermarking can be applied to text, images, audio, and video without reducing the quality of the work (Zhao, Guan, Huang, et al., 2020). QR Code (Quick Response Code) has an important role in storing information on an object. QR Code was first introduced in 1994 by the Japanese automotive company Denso Wave (Gopale, 2019).

Scientific works that have DOI already have a special digital sign, but there is no strong proof of ownership other than the identity of the researcher in the scientific work. In this study, we are interested in increasing copyright

* Corresponding author

This is an Creative Commons License This work is licensed under a Creative

Commons Attribution-NoDerivatives 4.0 International License. 


\section{Journal of Computer Networks, Architecture and High Performance Computing}

Volume 3, Number 2, July 2021

https://doi.org/10.47709/cnahpc.v3i2.1064
Submitted : 24 August 2021

Accepted : 25 August 2021

Published : 28 August 2021

protection of scientific works by embedding QR Code DOI on every scientific work that will be published.

\section{LITERATURE REVIEW}

One of the Watermarking algorithms that are often used by researchers is the DWT algorithm (Discrete Wavelet Transform). Research conducted by Qingtang Su, Amrit Anil using the DWT algorithm to improve data security and improve digital data security. The DWT algorithm has good performance such as visual imperceptibility and robustness. Qingtang Su examines the color image watermarking algorithm in spatial domain combining the principle of discrete Wavelet transform (DWT) is presented to embed color watermark image into color carrier image (Su et al., 2020). Amrit Anil researching to find out how digital watermarking role in improving the security of data on ordinary computing (Anil et al., 2020).

In addition to the DWT algorithm, many researchers also use the DCT algorithm (Discrete Cosine Transform), as is done by Limin Sun, Hsiang Cheh Huang. Limin Sun researches by protecting ownership of QR Code with DCT and SVD Watermarking Algorithm (Sun et al., 2021). Hsiang Cheh Huang researching with the DCT Watermarking algorithm, researchers carried out two watermark processes, the first watermark was using a QR code, and the second watermark was carried out in a binary random sequence to produce maximum document protection (Huang et al., 2020). Xuecheng Gong conducted research that combines the DCT and DWT methods to overcome the problem of small storage space and the resistance of color image watermarking (Gong \& Li, 2021). Umer Aziz Waqas researched by combining the Daubechies Wavelet Watermarking method and the Chaotic Map. This study aims to build efficient and effective multi-layer information data security. Watermarking that is formed not only acts as copyright protection but also authentications (Waqas et al., 2020).

Several researchers also researched Watermarking of Portable Document Format (PDF). Research conducted by Ahmad W Bitar, using the Spread Transform Dither Modulation (STDM) algorithm. This research can generate resistance and transparency (Bitar et al., 2017). Weijuan Zhao doing Watermarking research on PDF using the DES algorithm (Data Encryption Standart) (Zhao, Guan, \& Zhang, 2020). That research can result in better security and can withstand attacks from irresponsible parties. Yinguo Qiu researching to improve the durability of copyright documents by applying a multi-stage watermarking algorithm (Qiu \& Duan, 2021). Research shows effective protection with maximum data storage capacity. Ales Rocek conducts research on Zero Watermarking which aims to protect the integrity and ownership of medical images. The results show that Zero Watermarking can check the integrity of a medical image, but cannot distinguish which image has been modified or has been affected by other attacks from irresponsible parties (Roček et al., 2021).

Research on QR Code (Quick Response Code) is also often done in combination with other research fields, one of which is research conducted by Asma Shaikh. In this study, researchers use Machine Learning to detect malware in images and also QR Codes (Shaikh et al., 2021). In addition, there is also research that combines watermarking with QR Code, namely research conducted by Mohammed Hazim Alkawaz. This research is not only able to improve the security of copyright documents but is also able to direct users of this system to browse websites through QR Code scanning (Alkawaz et al., 2020).

\section{METHOD}

In this study, researchers used a DOI QR Code to be embedded in a PDF document of scientific work using the watermarking technique. The research diagram that can explain the flow of this research is as follows:

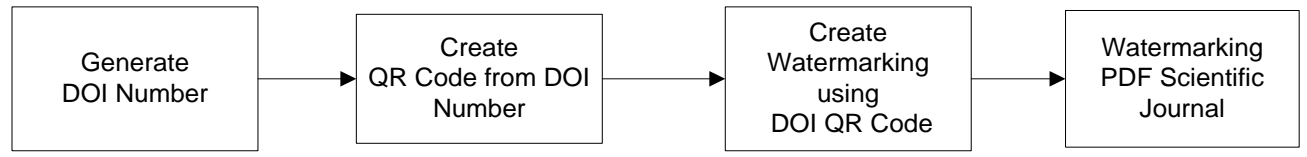

Fig 1. Proposed Method

In this study, researchers used tools from OJS (Open Journal System) to generate DOI numbers automatically according to the scientific work ID. In addition, researchers also use tools to create DOI QR Codes sourced from https://www.qrstuff.com/ and use tools to create watermarking PDF sourced from https://www.geeksforgeeks.org/addwatermark-to-pdf-using-pypdf4-in-python/. 


\section{Journal of Computer Networks, Architecture and High Performance Computing}

Volume 3, Number 2, July 2021

https://doi.org/10.47709/cnahpc.v3i2.1064
Submitted : 24 August 2021

Accepted : 25 August 2021

Published : 28 August 2021

\section{Generate DOI Number}

In the Generate DOI Number stage, DOI has generated automatically with the OJS (Open Journal System) system. DOI consists of several parts that indicate the identity of the publisher of the scientific work and also the identity of the scientific work. DOI numbers in Fig. 2 shows that this scientific paper has ID =963, where the ID number of this scientific paper is generated sequentially and each scientific work will not have the same ID. The DOI number in Fig. 2 indicates that this scientific work was published in the DST journal with volume 1 issue 1.

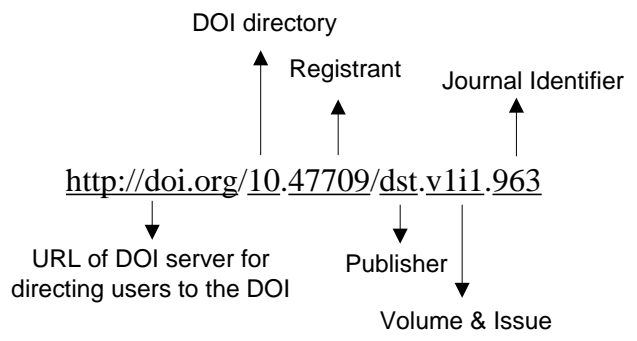

Fig 2. DOI Number

\section{Create QR Code from DOI Number}

After generating the DOI number, then a QR Code will be built from the DOI Number. The formation of the QR Code consists of several stages, namely (Prathivi, 2019):

Step - 1: Determine the capacity of the QR Code character to be stored

Step - 2: Encode data by specifying QR Code data type

Step - 3: Convert data to binary number

Step - 4: Calculate the maximum error correction rate of $30 \%$

Step -5 : The binary representation ( 0 and 1$)$ data and the error calculation result are allocated to

QR Code form

Step - 6: Data allocation in the QR Code follows the steps below:

Step - 6.1: Data in binary form is allocated into a matrix with the size according to the data capacity on QR Code version

Step - 6.2: The data is first placed in the lower right corner

Step - 6.3: The next data is placed on it following a zigzag pattern and so on

Step - 6.4: The data allocation (encode) process is carried out from bottom right to left side and top left so on vertically or horizontally

\begin{tabular}{|c|c|c|c|c|c|c|c|}
\hline 50 & 49 & 48 & $\pi_{47}$ & 18 & 17 & 16 & $\nabla_{15}$ \\
\hline & $\underline{z}$ & 4 & & 4 & $\Delta$ & 7 & \\
\hline 52 & 51 & 46 & $\checkmark 45$ & 20 & 19 & 14 & $\nabla_{13}$ \\
\hline 4 & & 7 & & 4 & $\pi$ & 7 & \\
\hline 54 & 53 & 44 & $\pi_{43}$ & 22 & 21 & 12 & $\nabla_{11}$ \\
\hline 4 & 2 & 4 & & & $\bar{\Delta}$ & 4 & \\
\hline 56 & 55 & 42 & 41 & 24 & 23 & 10 & $\nearrow_{9}$ \\
\hline 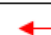 & $\pi$ & 4 & & & $\Sigma$ & 4 & \\
\hline 58 & 57 & 40 & 39 & 26 & 25 & 8 & $\pi_{7}$ \\
\hline 4 & $\underline{-4}$ & 4 & & & $\underline{-}$ & 7 & \\
\hline 60 & 59 & 38 & 37 & 28 & 27 & 6 & ${ }^{\top}$ \\
\hline & $\pi$ & 74 & & & $\Delta$ & 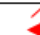 & \\
\hline 62 & 61 & 36 & 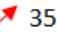 & 30 & 29 & 4 & $\pi 3$ \\
\hline & $\Delta$ & 7 & & & $\underline{x}$ & & \\
\hline 64 & 63 & 34 & 33 & 32 & 31 & 2 & 1 \\
\hline
\end{tabular}

Fig 3. Encode Data to QR Code 


\section{Journal of Computer Networks, Architecture and High Performance Computing}

Volume 3, Number 2, July 2021

https://doi.org/10.47709/cnahpc.v3i2.1064
Submitted : 24 August 2021

Accepted : 25 August 2021

Published : 28 August 2021

Step - 7: The data encoding process is carried out on each empty QR Code box (other than the 3 detection marker boxes, alignment markings, timing pattern, version information, format information, and quiet zone. For more details, see Fig. 4 to Fig 5.
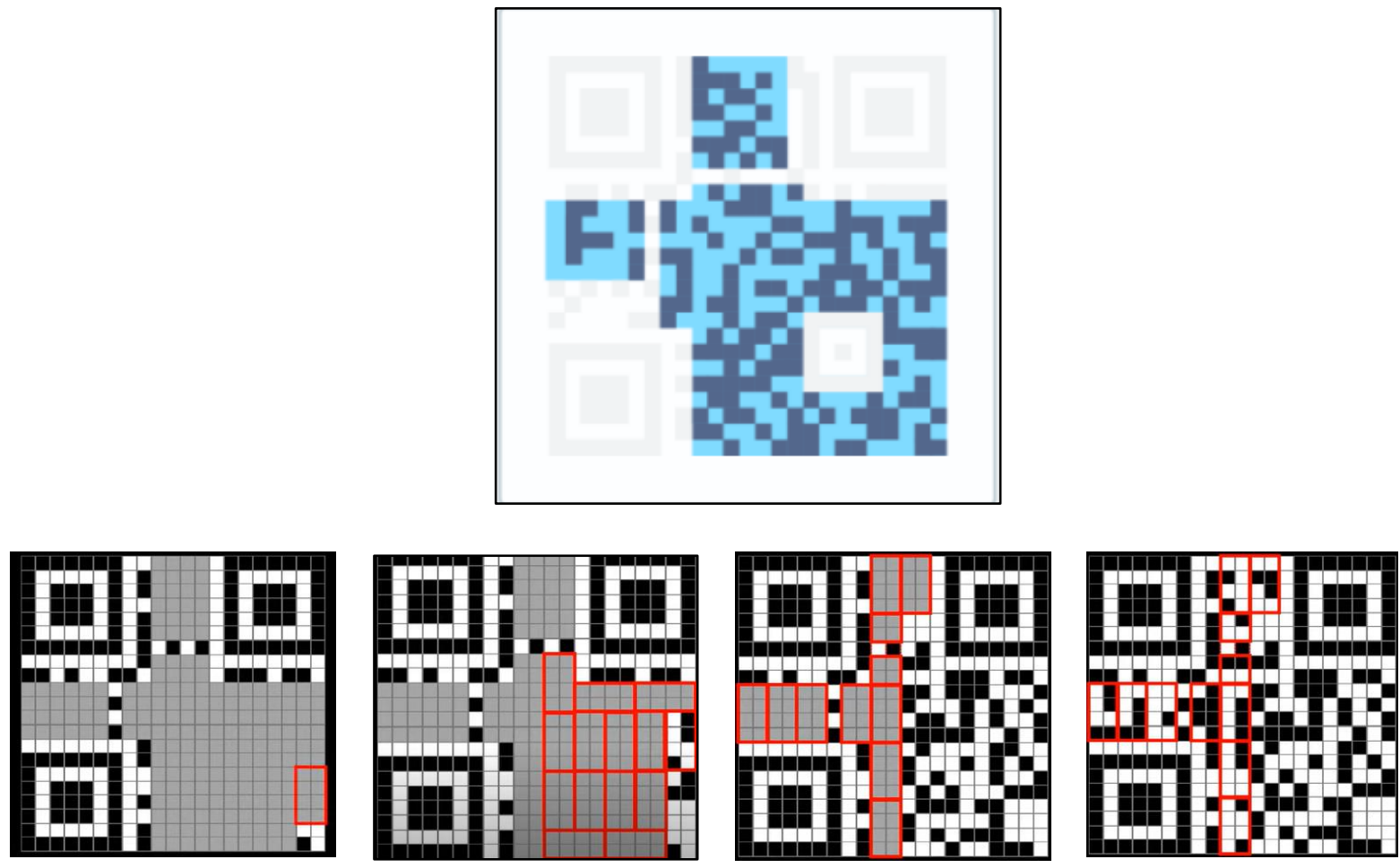

Fig 5. Process of Encode Binary Data to QR Code

(James, 2020)

\section{Create Watermarking using DOI QR Code}

After generating the DOI number and also building QR Code from the DOI number, the final stage is to watermark the PDF Scientific Journal. DOI QR Code is embedded in the left corner of the PDF Scientific Journal. The stages in watermarking are as follows:

Step - 1: Read Original PDF Scientific Journal

Step - 2: Read DOI QR Code

Step - 3: Embed QR Code to Original PDF Scientific Journal

Step - 4: Modify/Copy/Replace Process QR Code to Original PDF Scientific Journal

\section{RESULT}

Research testing is done by building a DOI QR Code and then embedding the QR Code in the PDF Journal with watermarking. After all the processes are complete, the last step is to check the results of the watermarking. The results of the DOI QR Code watermarking research are as shown in Table 1 below: 


\section{Journal of Computer Networks, Architecture and High Performance Computing}

Volume 3, Number 2, July 2021

https://doi.org/10.47709/cnahpc.v3i2.1064
Submitted : 24 August 2021

Accepted : 25 August 2021

Published : 28 August 2021

Table 1. Watermarking DOI QR Code

\begin{tabular}{llll}
\hline \multicolumn{1}{c}{ URL Journal } & QR Code \\
https://doi.org/10.47709/ \\
dst.v1i1.963
\end{tabular}

\section{DISCUSSIONS}

From the results of the research tests shown in Table 1, it can be seen that the DOI QR Code watermarking process and URL detection process in each scientific paper can be successful. In this study, the URL of scientific papers can be directly visited by scanning the QR Code listed at the top left corner of each journal. The URL detection test of scientific papers is also carried out with a distance of several $\mathrm{cm}$, but so far all QR Codes can be detected properly, even though they have different times. The QR Code format in the form of .PNG and vector, can make QR Codes easy to detect even though they are of different sizes (big/small). The results of this study are also as successful as research conducted by Rastri, reading the QR Code is done with the QR Code Reader application. Results of reading the QR Code on the book's ISBN, author, title, number of books cabinets, and willingness to run well. In the research we did, there were still obstacles in the application that we built so that the watermarking results obtained were not 


\section{Journal of Computer Networks, Architecture and High Performance Computing}

Volume 3, Number 2, July 2021

https://doi.org/10.47709/cnahpc.v3i2.1064
Submitted : 24 August 2021

Accepted : 25 August 2021

Published : 28 August 2021

optimal. One of the obstacles in question is that the PDF watermarking process can only be done if the QR Code also has a PDF format, in addition to this format, the PDF watermarking process is still difficult to do.

\section{CONCLUSION}

This study combines a Digital Object Identifier (DOI) with Quick Response Code (QR Code) technology to increase the security of copyright protection of scientific work. The results of the study show that the DOI QR Code can strengthen the ownership of scientific works well. Watermarking DOI QR Code is not only assessed for several things, such as identification of scientific works, as copyright protection of scientific work but also can be an alternative for other researchers in accessing a scientific work. This can be proven that by scanning the QR Code, researchers can directly visit the URL of the scientific work.

\section{REFERENCES}

Alkawaz, M. H., Aqila, N., \& Imran, I. (2020). Digital Watermark Copyright Protection with QR Code. International Journal on Perceptive and Cognitive Computing (IJPCC), 6(1), 19-23.

Anil, A., Shukla, V. K., \& Mishra, V. P. (2020). Enhancing Data Security Using Digital Watermarking. Proceedings of International Conference on Intelligent Engineering and Management, ICIEM 2020, 364-369. https://doi.org/10.1109/ICIEM48762.2020.9160090

Begum, M., \& Uddin, M. S. (2020). Digital Image Watermarking Techniques: A Review. Information (Switzerland), 11(2), 1-38. https://doi.org/10.3390/info11020110

Bitar, A. W., Darazi, R., Couchot, J. F., \& Couturier, R. (2017). Blind Digital Watermarking in PDF Documents using Spread Transform Dither Modulation. Multimedia Tools and Applications, 76(1), 143-161. https://doi.org/10.1007/s11042-015-3034-2

Gong, X., \& Li, W. (2021). A Color Image Blind Digital Watermarking Algorithm Based on QR Code. Computer Science \& Information Technology (CS \& IT), 67-75. https://doi.org/10.5121/csit.2021.110405

Gopale, V. B. (2019). QR Code and Useful Applications in Libraries. International Journal of Library and Information Studies, 9(4), 82-86. http://www.ijlis.org

Huang, H. C., Chen, Y. H., Chang, F. C., \& Tseng, C. T. (2020). Multi-Purpose Watermarking with QR Code Applications. LifeTech 2020 - 2020 IEEE 2nd Global Conference on Life Sciences and Technologies, 42-45. https://doi.org/10.1109/LifeTech48969.2020.1570618978

Khedmatgozar, H. R. (2020). Digital Identifiers in Scientific Publishing and E-Health. Medical Writing, 29(2), 74-78.

Paskin, N. (2010). Digital Object Identifier (DOIC). Encyclopedia of Library and Information Science, First Update Supplement, 114-125. https://doi.org/10.1201/9781420068030.ch14

Prathivi, R. (2019). Analisa Sistem Qr Code Untuk Identifikasi Buku Perpustakaan. Jurnal Pengembangan Rekayasa Dan Teknologi, 14(2), 37. https://doi.org/10.26623/jprt.v14i2.1225

Qiu, Y., \& Duan, H. (2021). A Novel Multi-Stage Watermarking Scheme of Vector Maps. Multimedia Tools and Applications, 80(1), 877-897. https://doi.org/10.1007/s11042-020-09776-8

Roček, A., Javorník, M., Slavíček, K., \& Dostál, O. (2021). Zero Watermarking: Critical Analysis of Its Role in Current Medical Imaging. Journal of Digital Imaging, 34(1), 204-211. https://doi.org/10.1007/s10278-020-00396-0

Shaikh, P. A., Kotavadekar, M. R., Sawant, M. S., \& Landge, M. S. (2021). Machine Learning Based Solution for the Detection of Malicious JPEG Image and QR Code. International Journal of Advanced Research in Science, Communication and Technology, 4(2), 580-583. https://doi.org/10.48175/ijarsct-1071

Su, Q., Wang, H., Liu, D. C., Yuan, Z., \& Zhang, X. (2020). A Combined Domain Watermarking Algorithm of Color Image. Multimedia Tools and Applications, 79(39-40), 30023-30043. https://doi.org/10.1007/s11042-02009436-x

Sun, L., Liang, S., Chen, P., \& Chen, Y. (2021). Encrypted Digital Watermarking Algorithm for Quick Response Code using Discrete Cosine Transform and Singular Value Decomposition. Multimedia Tools and Applications, 80(7), 10285-10300. https://doi.org/10.1007/s11042-020-10075-5

Waqas, U. A., Khan, M., \& Batool, S. I. (2020). A New Watermarking Scheme Based on Daubechies Wavelet and Chaotic Map for Quick Response Code Images. Multimedia Tools and Applications, 79(9-10), 6891-6914. https://doi.org/10.1007/s11042-019-08570-5

Zhao, W., Guan, H., Huang, Y., \& Zhang, S. (2020). Research on Double Watermarking Algorithm Based on PDF 


\section{Journal of Computer Networks, Architecture and High Performance Computing}

Volume 3, Number 2, July 2021

https://doi.org/10.47709/cnahpc.v3i2.1064
Submitted : 24 August 2021

Accepted : 25 August 2021

Published : 28 August 2021

Document Structure. Proceedings - 2020 International Conference on Culture-Oriented Science and Technology, ICCST 2020, 298-303. https://doi.org/10.1109/ICCST50977.2020.00064

Zhao, W., Guan, H., \& Zhang, S. (2020). Research and Implementation of Text Watermarking Technology Based on PDF Document Structure. International Journal of Frontiers in Sociology, 2(1), 1-9. https://doi.org/10.25236/IJFS.2020.020101

James, E. (n.d.). Playlists [YouTube channel]. YouTube. Retrieved August 21, 2021, from https://www.youtube.com/watch?v=142TGhaTMtI 